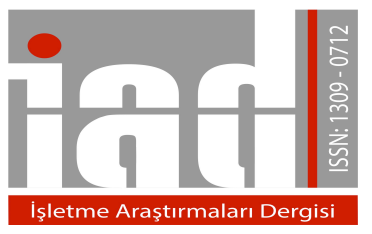

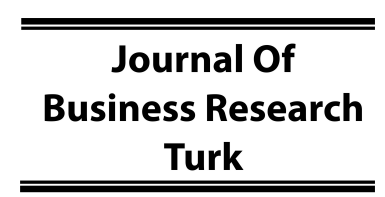

www.isarder.org

\title{
Yöneticinin Bilgi Paylaşım Davranışının, Çalışanların Bilgi Paylaşımı Sonucu Değersiz Olma Kaygısı Üzerindeki Etkisi ve Algılanan Örgütsel Desteğin Aracı Rolü Üzerine Bir Araştırma
}

\author{
The Effect of Knowledge Sharing Behavior of Supervisor on Employees' \\ Fear of Losing Value Regarding Knowledge Sharing: The Mediating Role \\ of Organizational Support
}

\author{
Gül Eser \\ Marmara Üniversitesi, \\ İşletme Bölümü \\ Ressam Namık İsmail Sok. No.1 \\ Bahçelievler/ İstanbul, Türkiye \\ guleser@marmara.edu.tr
}

\author{
M. Şebnem Ensari \\ Nişantaşı Üniversitesi, İktisadi İdari ve \\ Sosyal Bilimler Fakültesi, \\ Nişantaşı Kampüsü, Ergenekon Cad. No: \\ 45, Şişli / İstanbul, Türkiye \\ sebnemensari@gmail.com
}

\section{Özet}

Örgütlerde bilgi paylaşımı stratejik öneme sahip bir unsur olarak ele alınmakta ve bilgi paylaşımına engel olan unsurların ortadan kaldırılarak bireyin bilgisinin örgütün bilgisi haline getirilmesi için çeşitli çözüm önerileri geliştirilmektedir. Bilgi paylaşımının önündeki engellerden en önemlisinin çalışanın sahip olduğu bilgiyi paylaştıktan sonra gücünü ve eşsizliğini kaybedeceği kaygısının olabileceği savından hareketle mevcut araştırmada yöneticinin bilgi paylaşım davranışının bu kaygı üzerindeki etkisi ve bu ilişside örgütsel desteğin aracı rolü irdelenmiştir. Yöneticinin çalışanlar için kurumun kültürü ve davranış kodları hakkında ipucu sağlayan bir rol model olabileceği düşüncesi ile yöneticinin bu davranışının çalışanların kaygılarını azaltıcı rol oynayabileceği düşünülmektedir. Araştırmaya 217 çalışan katılmış olup analiz sonuçlarına göre, yöneticinin bilgi paylaşım davranışının çalışanların bilgi paylaşımı sonucu değersiz olma kaygısını azalttı̆̆g görülmüş ve örgütsel desteğin bu ilişkideki aracı rolü doğrulanmıştır.

Anahtar Kelimeler: Örgütsel destek, bilgi paylaşımı, yöneticinin bilgi paylaşımı, değersiz olma kaygisi

\section{Abstract}

Knowledge sharing has a strategic importance in organizations, therefore several solutions and suggestions are proposed to overcome the barriers regarding knowledge sharing and to enable the individual's knowledge to become the knowledge of the organization. We argue that the most important barrier to knowledge sharing is the fear of losing power and uniqueness that may occur after knowledge sharing, accordingly in this study we examine the effect of knowledge sharing behavior of supervisor and 
mediating role of organizational support. We suggest that supervisor will act as a role model for employees especially to understand the organizational culture and code of conducts and therefore knowledge sharing of supervisor will decrease employees' fear of losing value. 217 employees participated in our study and according to analysis knowledge sharing behavior of supervisor decreases employees' fear regarding knowledge sharing and also the mediating role of organizational support is revealed.

Keywords: Organizational support, knowledge sharing, knowledge sharing behavior of supervisor, fear of losing value

\section{Giriş}

Bireysel bilgi çalışanların zihninde yer alırken, örgütsel bilginin bölüm düzeyinde gerçekleştiği ve yapısal bilginin ise süreçler, el kitapları ve etik kurallar aracılığıyla kurumun tamamına yayıldığı ifade edilmektedir (O'dell vd., 2003). Araştırmacılar bireysel bilginin, örgütün yapısal bilgisine dönüştürülmesine kısacası bilgi paylaşım sürecinin önemine dikkat çekmektedirler (Nonoka,1991,1994; Davenport ve Prusak, 1998; Holtshouse, 1998).

Çalışanlar açısından yöneticinin örgütün bütününü temsil ettiği varsayımından hareketle, bilgi paylaşımı ve bilginin örgütün yapısal bilgisine dönüştürülmesi konusunda yöneticinin rolünün sıklıkla inceleme konusu yapıldığı görülmektedir (Nonaka, 1994; Nigel vd, 1999; Dfouni ve Croteau, 2003; Connelly ve Kelloway 2003). $\mathrm{Bu}$ bağlamda, yöneticinin bilgi paylaşım davranışının, algılanan örgütsel destek ve örgüt içerisinde bireysel bilginin paylaşımı üzerinde de etkili olacağı düşünülmektedir. Yöneticisinin kendisiyle bilgi paylaştığını düşünen çalışanın, daha fazla örgütsel destek hissedeceği ve örgütün onu gözden çıkarmak niyetinde olmadığını düşüneceği varsayılmaktadır. Daha fazla örgütsel destek algılayan bireyin ise diğer örgüt çalışanları ile bilgi paylaşmaktan çekinmeyeceği ve bilgi paylaşımının artacağı öngörülmektedir.

Örgütsel destek çalışanların kurumlarının onları ve çabalarını önemsediğine ve bu çabaların karşılıksız kalmayacağına dair inançlarını yansıtmaktadır. $\mathrm{Bu}$ inanç karş1lıklılık ilkesi gereği çalışanın kendisini kurumuna karşı borçlu hissetmesine ve kurumuna elinden geldiğince geri ödeme yapmasına yol açmaktadır. Yazında bu geri ödeme biçimleri örgüte bağlılık, işten ayrılma niyetinin azalması, güven ve bilgi paylaşımının artması gibi çeşitli kavramlarla ilişkilendirilmiş ve örgütsel desteğin kurumların ve çalışanların esenlik ve iyilikleri açısından önemli bir kavram olduğu vurgulanmıştır.

Çalışanların yöneticileri olan ilişkilerini ve bu ilişkiden çıkardıkları anlamları örgütün tamamına atfettikleri bilinmektedir. Yönetici bir anlamda kurumdaki genel uygulamalar ve kabul edilebilir davranış normları hakkında çalışana bilgi sağlayan kilit bir pozisyonda yer almaktadır. Bu nedenle örneğin yöneticinin şeffaflık ilkesini benimsemesi, çalışanları ile açı iletişimde olması ve bilgi paylaşımı konusunda istekli ve cesaretlendirir bir tavır sergilemesi çalışanların da açık iletişim ve bilgi paylaşımını benimsemelerini sağlayabilecektir.

Bilgi paylaşımının önündeki en büyük engel ve kısıtlayıcının, çalışanların kendilerine belki de pazarlık gücü sağlayan mesleki bilgi ve birikimlerini paylaşmak durumunda ellerinde gücü kaybedecekleri kaygısı gelmektedir. Bu kaygıyla çalışanın çaba ve emek harcayarak elde ettiği bilgiyi kendine saklamak istemesi, böylece vazgeçilmez ve yedeklenemez bir konuma gelmek istemesi söz konusu olabilir. Bu 
engelin aşılmasında en önemli unsur ise kurumun kültürünü yansıtarak rol model olan yöneticinin bilgi paylaşımı konusundaki tavrıdır. Yöneticisinin bilgi paylaşmakta olduğunu gözlemleyen bir çalışan bilginin güce eşit olduğu şartlamasını ortadan kaldırarak korkusuzca bilgisini paylaşabilecektir.

Yöneticinin açık bir iletişim ortamında bilgisini paylaşması çalışanın algıladığı örgütsel desteğin artmasını sağlayacak bu durum ise çalışanın geri ödeme zorunluluğu hissetmesini doğuracak ve sonuç olarak çalışanın bilgi paylaşım davranışı artacak yani bilgi paylaşımı sonucu değersiz olma kaygısı azalacaktır.

\section{Yöneticinin Bilgi Paylaşımı ve Çalışanın Bilgi Paylaşımı Sonucu Değersiz Olma Kaygısı}

Steve Jobs, 1998 yılında Fortune dergisine yaptığı bir açıklamada diyor ki;

"Yenilikçilik, Arge’ye ne kadar para harcadiğınla ilgili değildir. Hangi insanlara sahipsin, onlart nasıl yönetiyorsun ve sonucunda ne elde ediyorsun bununla ilgilidir." (Kirckpatrick,1998)

$\mathrm{Bu}$ sözüyle Steve Jobs, bireylerin bilgisini yönetmenin işletmeler için ne kadar önemli bir konu olduğuna vurgu yapmaktadır. İlgili literatürde, bireylere ait enformasyonun süreçlere bilgi olarak kazandırılması süreci yani bilginin paylaşılarak örgüt bilgisi haline getirilmesi konusuna pek çok kere vurgu yapılmaktadır. Nonoka'nın $(1991,1994)$ bilgi döngüsünden hareketle; bilgini yaratılması sürecinde, saklı bilginin açık bilgiye dönüştürülmesi bilgi paylaşımı olarak tanımlanmaktadır. Holtshouse'a (1998) göre, bilgi paylaşımı bireysel bilginin grup bilgisi haline çevrilme sürecidir. Ancak Davenport ve Prusak'ın (1998) belirttiği gibi örgüt içerisinde bilginin paylaşılmasını sağlamak ve dağıtmak çok kolay değildir. Szulanski (1996), Leonard ve Sensiper (1998), Trauth (1999), Stenmark (2000), ilerisini düşünen bir bireyin mevcut gücünü ve rekabetçi konumunu kaybetme korkusu, bir başka ifade ile işini güvence altında tutma gerekliliği nedeniyle bilgilerini paylaşma konusunda direnç gösterebileceğini ve bilgilerini kendilerine saklayabileceklerini belirtmektedirler. Baskerville ve Dulipovici (2006) bu durumu şu şekilde açıklamaktadırlar;

“ Bireysel bilgi, başkalarına aktarıldiğı zaman daha az değerli olmaya başlar. Bu bilgi, bireyin zenginliğin veya sosyal statüsünün kaynağl olabilir ve bu tür bilginin transferi sonucu bireyin değersizleştiğini gözlemleyebilirsiniz. Bu bilginin kaynă̆ bireyin hayat tecrübesi olabilir ve bu tür bilginin transferi telif haklart ile korunan bilgilerin geliştirilmesi ile aynı şekilde olmaz”.

Renzl (2008), bireyin örgüt için olan değerini kaybetme korkusunun/değersiz olma kaygısının, bilgi paylaşımını ve saklı bilgilerini örgüt için işe yarayacak şekilde dökümante etme davranışını etkilediğini belirtmektedir. Constant vd.(1994) ve Trauth (1999), örgüt içinde yaratılan bilgi paylaşımı konusundaki kültüre dikkat çekmektedir. Bu noktada, örgüt içerisinde örgütü temsil eden yönetici ya da liderin üzerinde önemle durulduğu görülmektedir. Çalışanların, örgütün vekili olan yöneticinin genel davranış ve tutumunu örgütün bütününe atfettikleri belirtilmektedir (Eisenberger vd. 1986 içinde Howes vd. 2000; Sluss, 2008; Baranik vd. 2010). Çalışan, yöneticiyi örgütün vekili olarak algılamakta ve yöneticinin kendilerine yönelik davranışlarından örgütün kendisine verdiği değer hakkında bir algı geliştirmektedir. Bunun sonucu olarak, liderlik, bir öğrenme kültürü oluşturmada ve bu kültürü sürdürmede önemli bir unsur olarak karsımıza çıkmaktadır. Swap vd (2001), bir örgüt içerisinde saklı bilginin açığa 
çıkarılması ve transfer sürecinde bireylerin informal öğrenme ve öğretme şekillerine vurgu yapmaktadırlar. Bu noktada da yönetimin "mentorluk etme" ve "hikaye anlatma" yoluyla bilgi transferi kültürünü en kolay ve en anlaşılabilir şekilde yayabileceğine dikkat çekmektedirler. Hislop (2003) ve Oldham (2003) çalışmalarında örgüt içerisinde bilgi paylaşım kültürü yaratmanın önemine dikkat çekmekte ve supervizörlerin desteğinin örgüt içerisinde bilgi paylaşımını güçlendirdiğine dikkat çekmektedirler. Yazında, mentörlüğün işletme perfromansının arttırdığına dair çalışmalar, performanstaki artışın aslında mentörlüğün değil bilginin paylaşımı sonucunda gerçekleştiği sonucunu ortaya koymaktadır. Dfouni ve Croteau'a (2003) göre, lider, tek başına örgütün kültürünü değiştiremez ancak liderin, bilgi paylaşımı için gerekli olan kültürel değişimin öncülügüünü yapması gerekmektedir. Connelly ve Kelloway (2003), "Predictors Of Employees' Perceptions of Knowledge Sharing Cultures" adl çalışmalarında, bilgi paylaşımı konusunda yöneticinin desteği olduğu algısının örgüt içerisinde bilgi paylaşımını etkilediğini göstermişlerdir. Doğan ve Kılıç, örgüt içindeki çalışanların, diğer çalışanlar ile bilgi paylaşımını destekleyici bir ortam yaratılması sürecinde bilgi paylaşımının teşvik edilmesinin liderin önemli bir görevi olduğunu vurgulamaktadır (2009). Ayrica, Holste ve Fields (2010), Nahapiet ve Ghoshal(1998)'ın tanımladığı güven ve bilgi transferi ilişkisinden etkilenerek, bireylerin etkileşim esaslı güven ilişkileri içinde olduğu (diğer kişiler tarafından önemsenmek ve kollanmaktan kaynaklanan güven) kişilerden aldıkları bilgileri daha çok paylaşmaya, bilişsel tabanlı güven ilişkisi (diğer kişinin yeterli ve güvenir olduğuna dayanana güven) içinde olduğu kişilerden aldıkları bilgileri daha çok kullanmaya meyilli olduklarını saptamışlardır. Bu sonucu, özellikle profesyonel çalışanların saklı bir bilgiyi kullanmasının paylaşmaktan daha riskli olduğu şeklinde yorumlamışlar, kulaktan dolma bilgiyi kullanan profesyonelin daha sonra yaşanabilecek hataların üstesinden gelmekte zorlanabileceklerini vurgulamışlardır.

\section{Algılanan Örgütsel Destek}

Örgütsel destek teorisi, örgütün çalışanların katkılarına ne kadar değer verileceğine ve esenliklerinin önemseyeceğine ilişkin çalışanların genel bir inanç geliştirdiklerini varsaymaktadır. Karşılıklılık ilkesine göre, örgütsel destek hisseden çalışanlar da örgütlerinin refahını önemsemek konusunda bir zorunluluk hissedecek ve örgüte amaçlarına ulaşmak konusunda destek olacaktır (Eisenberger vd.,2001).

Eisenberger vd. (2001) algılanan örgütsel desteği, örgütün politika, norm, prosedür ve eylemlerine ilişkin yardımsever ya da art niyetli olmasına ilişkin deneyime bağlı olarak gelişen bir özellik olarak tanımlamışlardır. Algılanan örgütsel destek çalışanlar ve örgütler açısından büyük önem taşımaktadır. Çünkü çalışanların örgüte bağl1lıklarının büyük ölçüde örgütlerinin kendilerine olan bağlılığından etkileneceği düşünülmektedir (Eisenberger vd. 1986).

Algılanan örgütsel desteğin karş1lıklılık normu gereği örgütsel bağlamda en önemli konulardan birisi olduğu, çalışanın örgütünün iyi muamelesine karşılık vermek zorunda hissettiği böylece çalışanların iş tatmini arttırarak örgüte bağlilıklarının arttıran bir unsur olduğu ifade edilmekte ve araştırma sonuçları da bu savı desteklemektedir (Mabasa ve Ngirande, 2015). Örgütsel desteğin örgüte yönelik proaktif davranışlar (Caesens vd. 2016), örgüte bağlılık (Dursun, 2016), işten ayrılma niyeti (Kalidass ve Bahron, 2015), örgütsel öğrenme düzeyi (Durmuş ve Şahin, 2015), bilgi paylaşım 
yoğunluğu, bilgi paylaşımından elde edilen tatmin (Lumbantobing,2015) gibi değişkenler üzerindeki etkisi çeşitli araştırmalara konu olmuştur.

Çalışanların örgütsel destek hissetmelerini sağlayan temel unsurların; yönetici desteği, ödül ve uygun iş koşulları, adil politika ve uygulamalar olduğu belirtilmektedir (Rhoades ve Eisenberger, 2002 aktaran: Khurram,2009). Bunların dişında tüm yatay ve dikey ilişkilerin, özellikle lider ile olan ilişkilerin algılanan örgütsel destek üzerine önemli bir etkiye sahip olabileceği ifade edilmektedir (Lumbantobing,2015).

Janz and Prasarnphanich (2003)'ın çalışmasının bir sonucu olarak, bireyler örgütsel desteği, sıcaklığı, bilgilendirmeyi, takdir edilmeyi hissettikleri ve risk aldıkları konularda sorun yaşarlarsa bunun problem olmayacağını bildikleri sürece, bireylerin bağımsılıkları ve bunun sonucu olarak birlikte öğrenme ve örgüt performansı artacaktır. Cabrera ve Cabrera (2005), benzer şekilde bilgi paylaşımının desteklemenin bilgi paylaşımına dayalı bir çevre oluşturduğu ve bilgi paylaşımını arttırdığını gösteren bir model oluşturmuşlardır. Watson ve Hewet (2006) ise çalışmalarında, Blau (1964) yılında geliştirdiği “Sosyal Değişim Teorisi”nden faydalanarak, ödüllendirilmeyen bilgi paylaşımını neden insanların kabul ettiğini örgütsel desteği hissetmek ile ilişskilendirmişlerdir.

\section{Araştırmanın Amacı ve Modeli}

$\mathrm{Bu}$ çalışmanın amacı, örgütün vekili olarak ele alınan yöneticinin bilgi paylaşım davranışının, çalışanların bilgi paylaşımları sonucu değersiz olma kaygısı üzerindeki etkisini incelemek ve bu süreçte algılanan örgütsel desteğin aracı rolünü irdelemektir. Araştırmanın amacı kapsamında geliştirilen model şekil 1 de gösterilmiştir.

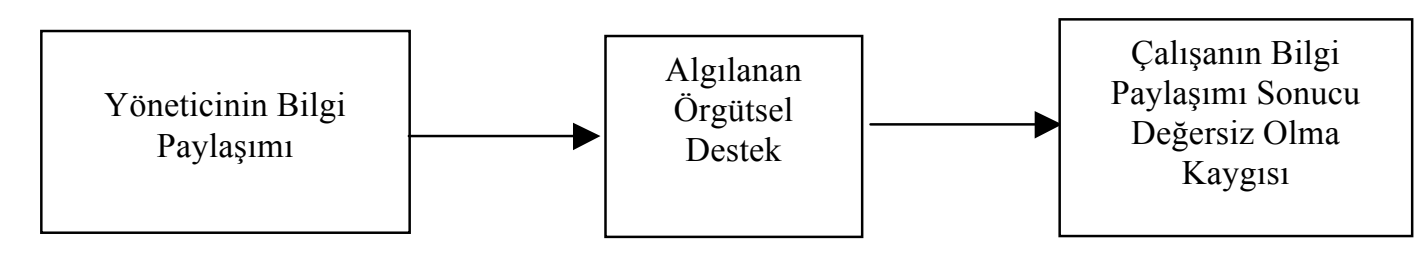

Şekil 1.Teorik Model: Yöneticinin Bilgi Paylaşımının, Çalışanın Bilgi Paylaşımı Sonucu Değersiz Olmak Kaygısı Üzerindeki Etkisi, Algılanan Örgütsel Desteğin Aracı Rolü

\section{Araştırmanın Yöntemi}

Araştırmada ölçüm aracı olarak anket kullanılmıştır. Anket kişisel bilgi formu, yöneticinin bilgi paylaşımı, algılanan örgütsel destek ve işini kaybetme korkusu olmak üzere 4 kısımdan oluşmaktadır. Kişisel bilgi formunda katılımcıların yaşı, cinsiyeti, medeni durumu gibi 7 soru yer almaktadır. Algılanan örgütsel desteği ölçmek için Eisenberger vd. (1986)'in 8 ifadeden oluşan ölçeği kullanılmıştır. Yöneticinin bilgi paylaşımını ölçmek için, Gee-Woo ve diğerlerinin (2005) bireyin bilgi paylaşımına dair 7 ifadeden oluşan ölçeği kullanılmıştır. Bilgi paylaşımına bağlı olarak değersiz olma kaygısı ise Renzl (2008)'in 4 ifadeden oluşan ölçeği ile ölçülmüştür. Katılımcılardan "Kesinlikle katılmiyorum" (1) dan "kesinlikle katılıyorum" (5) a uzanan bir aralıkta ifadeleri değerlendirmeleri istenmiştir. Verilerin çözümlenmesinde SPSS 16.0 paket programından yararlanılmış olup; demografik özelliklere ilişkin bilgilerin sunulması 
için frekans analizi, değişkenlerin alt boyutlarını ortaya koymak amacıyla faktör analizi, değişkenler arasındaki ilişkilerin sergilenemebilmesi için korelasyon analizi ve son olarak araştırmanın modelini test etmek amacıyla regresyon analizi ve Sobel test uygulanmıştır.

\section{Örneklem}

Araştırma İstanbul ilinde yürütülmüş olup, katılımcılar kolay ulaşılabilir örneklem yoluyla seçilmiştir. Katılımcılardan bir yönetici ile birebir çalışıyor olmak ve gün içinde yöneticisi ile etkileşimde olmak (örneğin rapor vermek) şartı aranmıştır. Katılımcıların çoğunluğunu (N:194) özel sektör çalışanları oluşturmakta olup, kamu sektöründen (N:23) sınırlı sayıda katılımcıya ulaşılabilmiştir. Örneklemin kolayda örneklem yoluyla seçilmiş olması ve çalışmanın belirli bir sekör/firma özelinde gerçekleştirilememiş olması çalışmanın bir kısıtı olarak belirtilebilir. Araştırma kapsamında toplamda 230 kişiye ulaş1lmış olup, anketlerin 13'ü eksik doldurma nedeniyle araştırma kapsamı dışında bırakılmıştır. Sonuç olarak 217 kullanılabilir anket ile analizler tamamlanmıştır.

\section{Demografik Özelliklere İlişkin Bulgular}

Katılımcıları tanımaya yönelik olarak anket formunun 1. kısmında yer alan sorulara alınan cevaplar frekans analizine tabi tutulmuştur. Frekans analizi sonucunu göre, katılımcıların \% 41,9'u kadın ve \%58,1'i erkektir. \%44,7'si evli ve \%55,3'ü bekardır. \%3,2'si ilköğretim, \%11,1'i lise, \%60,4'ü üniversite, \%20,3'ü yüksek lisans ve $\% 5,1$ 'i doktora eğitimine sahiptir. $\% 25,8$ 'i alt kademe $\% 55,3$ 'ü orta kademe ve \%18,9'u üst kademede yer almaktadır. \%10,6's1 kamu ve \% 89,4'ü özel sektörde çalışmaktadır. İş deneyimlerinin 1 ile 41 yıl arasında değiştiği görülmektedir. Mevcut işyerlerindeki çalışma süreleri ise 1 ile 28 yıl arasında değişmektedir.

\section{Ölçeklerin Güvenilirlikleri}

Anket formunda yer alan tüm ölçeklere ilişkin güvenilirlik analizi değerleri tablo 1 'de sunulmuştur.

Tablo 1. Güvenilirlik ve Ortalama Değerler

\begin{tabular}{|lcc|}
\hline Değişkenler & Soru Sayısı & Güvenilirlik \\
\hline Yöneticinin Bilgi Paylaşımı & 7 & $\mathbf{. 8 9 2}$ \\
\hline Algılanan Örgütsel Destek & $\mathbf{8}$ & $\mathbf{. 8 7 1}$ \\
\hline Bilgi Paylaşımı Sonucu Değersiz Olma Kaygısı & 4 & $\mathbf{. 8 4 0}$ \\
\hline
\end{tabular}

\section{Yöneticinin Bilgi Paylaşımına İlişkin Faktör Analizi}

Yöneticinin bilgi paylaşımına ilişkin 7 soru faktör analizine tabi tutulmuştur. 7 ifade için KMO değeri 0.856 ve Bartlett's test değeri 0.000 olduğu için ifadelerin faktör analizine uygun olduğu görülmüştür. Faktör analizi sonucunda sorular ölçeğin aslına uygun olarak tek bir boyut altında toplanmıştır. $\mathrm{Bu} 7$ soru ile yöneticinin bilgi paylaşımının varyansının $\% 60.803$ oranında açıklandığı belirlenmiştir. 


\section{Algılanan Örgütsel Desteğe İlişkin Faktör Analizi}

Algılanan örgütsel desteğe ilişkin 8 ifade için KMO değeri 0.828 ve Bartlett's test değeri 0.000 olduğu için algılanan örgütsel destek ifadeleri faktör analizine uygun görülmüştür. Yapılan faktör analizi sonucunda sorularının ölçeğin aslına uygun olarak tek boyut altında toplanmıştır. Bu 8 soruyla algılanan örgütsel desteğin varyansının \%53.911 oranında açıklandığı belirlenmiştir.

\section{Bilgi Paylaşımı Sonucu Değersiz Olma Kaygısına İlişkin Faktör Analizi}

Bilgi paylaşımı sonucu değersiz olma kaygısına ilişkin 4 ifadenin KMO değeri 0.751 ve Bartlett's test değeri 0.000 olduğu için ifadeler faktör analize uygun bulunmuştur. Ölçekteki 4 soru tek bir boyut altında toplanmış ve sorunların ölçeğin varyansın \%69.077 oranında açıklandığı belirlenmiştir.

\section{Korelasyon Analizi}

Değişkenler arasındaki ilişkilerin değerlendirilmesi amacıyla korelasyon analizi uygulanmıştır. Korelasyon analizi sonucunda, yöneticinin bilgi paylaşımı davranışı ile örgütsel destek arasında pozitif yönde bir ilişkinin olduğu görülmüştür. Yöneticinin bilgi paylaşımı ile bilgi paylaşımı sonucu değersiz olma kaygısı arasında negatif yönlü bir ilişki, yine algılanan örgütsel destek ile bilgi paylaşımı sonucu değersiz olma kaygısı arasında negatif yönlü bir ilişkinin olduğunu görülmektedir.

Korelasyon analizi sonucunda yöneticinin bilgi paylaşımının arttıkça çalışanların algılanan örgütsel desteklerinin arttığı ve değersiz olma kaygılarının azaldığ1 söylenebilir. Ayrıca algılanan örgütsel destek arttıkça, değersiz olma kaygısı da azalmaktadir.

Tablo 2: Korelasyon Analizi Sonucu

\begin{tabular}{|l|c|c|c|c|c|}
\hline \multicolumn{1}{|c}{ Değişken } & Ort. & S.S. & 1 & 2 & 3 \\
\hline Yöneticinin Bilgi Paylaşımı & 3,4905 & .78447 & 1 & & \\
\hline Örgütsel Destek & 3,6515 & .73766 & $.638^{* *}$ & 1 & \\
\hline $\begin{array}{l}\text { Bilgi Paylaşımı Sonucu Değersiz } \\
\text { Olma Kaygısı }\end{array}$ & 1,8675 & .77131 & $-.150^{*}$ & $-.302 * *$ & 1 \\
\hline
\end{tabular}

$*_{p}<.05 ; * * p<.01$

\section{Regresyon Analizi}

Yöneticinin bilgi paylaşımı davranışının, çalışanın bilgi paylaşımı sonucu değersiz olma kaygısı üzerindeki etkisinde algılanan örgütsel desteğin aracı rolünü ortaya koymak amaciyla ara değişken testleri (Baron ve Kenny, 1986) SPSS ile sınanarak yapılmıştır. Buna göre istatistikî açıdan örgütsel desteğin bir ara değişken rolü oynadığını ortaya koyabilmek için 3 ayrı regresyon analizi uygulnmalıdır. Modeli kapsamın örgütsel desteğin aracı rolü olduğunu göstermek için;

- Yöneticinin bilgi paylaşımı davranışının çalışanın bilgi paylaşımı sonucu değersiz olma kaygısı üzerinde,

- Yöneticinin bilgi paylaşımı davranışının örgütsel destek üzerinde, 
- Yöneticinin bilgi paylaşımı davranışının örgütsel destekle birlikte çalışanın bilgi paylaşımı sonucu değersiz olma kaygısı üzerindeki etkisinde yalnızca örgütsel desteğin katkısının olması gerekmektedir.

Birinci aşama için yöneticinin bilgi paylaşımı davranışının çalışanın bilgi paylaşımı sonucu değersiz olma kaygısı üzerindeki katkısını görmek üzere regresyon analizi uygulanmıştır. Analize ilişkin sonuçlar tablo3'te sunulmaktadır. Analiz sonuçlarına göre modelin açıklayıcılığının istatistiki olarak anlamlı ancak oldukça düşük olduğu (p: 0.02; Adj.R squ.: ,018) görülmektedir. Yöneticinin bilgi paylaşımı davranışının, çalışanın bilgi paylaşımı sonucu değersiz olma kaygısına düşük düzeyde ve negatif katkısının (Beta:-,150) olduğu görülmektedir.

Tablo 3. Yöneticinin Bilgi Paylaşım Davranışı ile Çalışanın Bilgi Paylaşımı Sonucu Değersiz Olma Kaygısı Arasındaki Regresyon Analizi Sonuçları

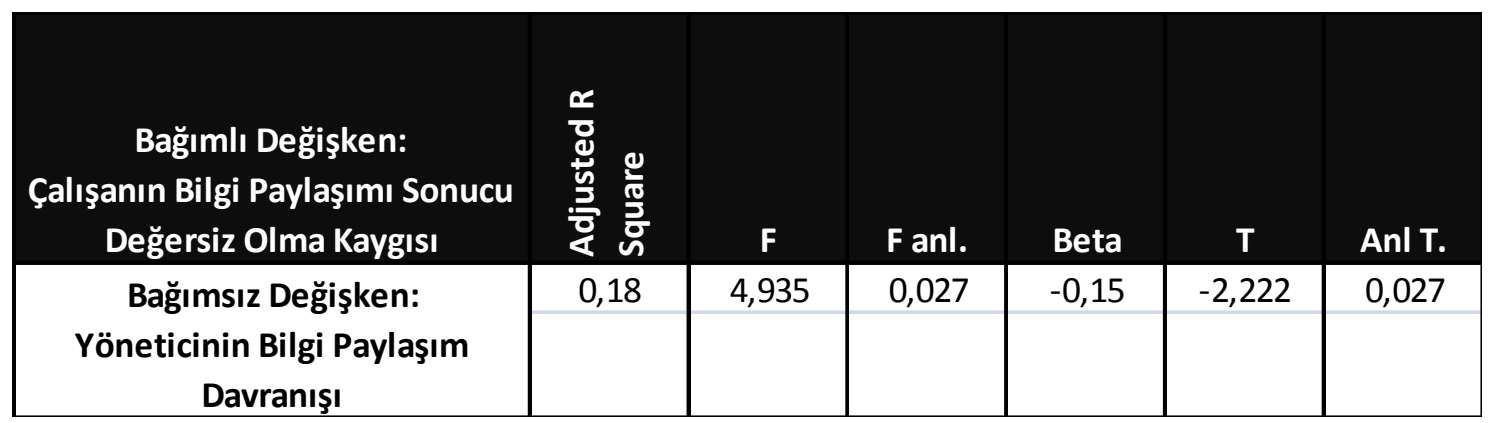

İkinci aşamada yöneticinin bilgi paylaşımı davranışının algılanan örgütsel destek üzerindeki katkısını görmek üzere regresyon analizi uygulanmıştır. Analize ilişsin sonuçlar tablo 4'te sunulmaktadır. Analiz sonuçlarına göre modelin açıklayıcılığının istatistiki anlamlı olduğu (p: .000; Adj.R squ.: ,404) görülmüştür. Yöneticinin bilgi paylaşımı davranışının, algılanan örgütsel destek üzerinde pozitif yönde yüksek bir katkıya sahip olduğu (Beta:,638) görülmektedir.

Tablo 4.Yöneticinin Bilgi Paylaşım Davranışı ile Algılanan Örgütsel Destek Arasındaki Regresyon Analizi Sonuçları

\begin{tabular}{|c|c|c|c|c|c|c|}
\hline $\begin{array}{c}\text { Bağımlı Değişken: } \\
\text { Algılanan Örgütsel } \\
\text { Destek }\end{array}$ & 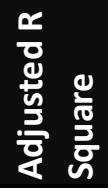 & $\mathbf{F}$ & $F$ anl. & Beta & $\mathbf{T}$ & Anl T. \\
\hline \multirow{2}{*}{$\begin{array}{c}\text { Bağımsız Değişken: } \\
\text { Yöneticinin Bilgi Paylaşım } \\
\text { Davranışı }\end{array}$} & 0,404 & 147,515 & 0,000 & 0,638 & 12,146 & 0,000 \\
\hline & & & & & & \\
\hline
\end{tabular}

Üçüncü aşamada yöneticinin bilgi paylaşımı davranışı ve algılanan örgütsel desteğin her ikisinin çalışanın bilgi paylaşımı sonucu değersiz olma kaygısı üzerindeki açıklayıcı katkısını görmek üzere regresyon analizi uygulanmıştır. Elde edilen sonuçlar tablo 5'te sunulmuştur. Elde edilen sonuçlara göre, model istatistiki olarak anlamlı olmakla beraber ( $\mathrm{F}$ anl: .000), yöneticinin bilgi paylaşımı davranışının bilgi paylaşımı sonucu değersiz olma kaygısı üzerinde istatistiki olarak açıklayıcı katkısı yoktur (p: .390). Bu sonuç, algılanan örgütsel desteğin bir ara değişken olarak rol oynadığ anlamina gelmektedir. 
Tablo 5. Yöneticinin Bilgi Paylaşım Davranışı ve Algıılanan Örgütsel Destek ile Çalışanın Bilgi Paylaşımı Sonucu Değersiz Olma Kaygısı Arasındaki Regresyon Analizi Sonuçları

\begin{tabular}{|c|c|c|c|c|c|c|}
\hline $\begin{array}{c}\text { Bağımlı Değişken: } \\
\text { Çalışanın Bilgi Paylaşımı Sonucu } \\
\text { Değersiz Olma Kaygısı }\end{array}$ & 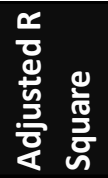 & $\mathbf{F}$ & F anl. & Beta & $\mathbf{T}$ & Anl T. \\
\hline Bağımsız Değişken: & 0,086 & 11,186 & 0,000 & 0,073 & 0,862 & 0,390 \\
\hline $\begin{array}{c}\text { Yöneticinin Bilgi Paylaşım } \\
\text { Davranışı }\end{array}$ & & & & & & \\
\hline Bağımsız Değişken: & & & & $-0,349$ & $-4,131$ & 0,000 \\
\hline $\begin{array}{c}\text { Algılanan } \\
\text { Örgütsel Destek }\end{array}$ & & & & & & \\
\hline
\end{tabular}

Son olarak algılanan örgütsel desteğin çalışanın bilgi paylaşımı sonucu değersiz olma kaygısı üzerindeki katkısını görmek üzere regresyon analizi uygulanmıştır. Analize ilişkin sonuçlar tablo 6'de sunulmaktadır. Analiz sonuçlarına göre modelin açıklayıcılığının anlamlı ancak oldukça düşük olduğu (p: .000; Adj.R squ.: ,087) görülmüştür. Algılanan örgütsel desteğin, çalışanın bilgi paylaşımı sonucu değersiz olma kaygısı üzerinde negatif ve orta düzeyde bir katkıya sahip olduğu (Beta: -,302) görülmektedir.

Tablo 6.Algılanan Örgütsel Desteğin Çalışanın Bilgi Paylaşımı Sonucu Değersiz Olma Kaygısı Arasındaki Regresyon Analizi Sonuçları

\begin{tabular}{|c|c|c|c|c|c|c|}
\hline $\begin{array}{c}\text { Bağımlı Değişken: } \\
\text { Çalışanın Bilgi paylaşımı Sonucu Değersiz } \\
\text { Olma Kaygısı }\end{array}$ & 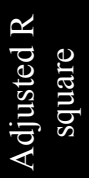 & $\mathrm{F}$ & $\begin{array}{c}\mathrm{F} \\
\text { anl. }\end{array}$ & Beta & $\mathrm{T}$ & Anl. $\mathrm{t}$ \\
\hline $\begin{array}{c}\text { Bağımsız Değişken: Algılanan Örgütsel } \\
\text { Destek }\end{array}$ & ,087 & 21,655 &, 000 &,- 302 & $-4,653$ &, 000 \\
\hline
\end{tabular}




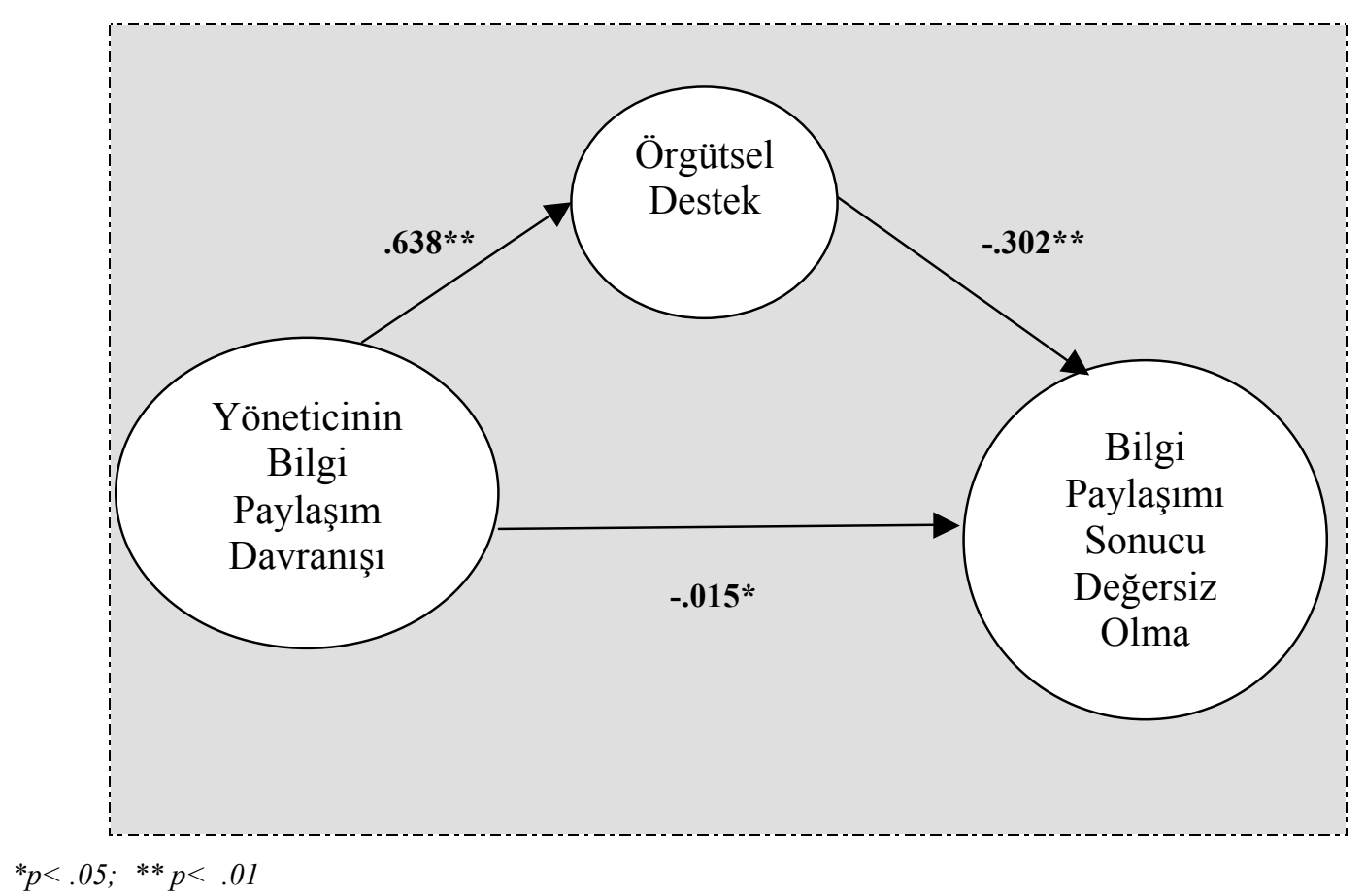

Şekil 2: Sobel Testinde Kullanılan Değerler

Örgütsel desteğin aracı rolünü test etmek üzere Sobel testi yapılmıştır. Elde edilen Sobel test istatistiği (Test istatistiği: -4.3320 ; standart hata $=0.043 ; \mathrm{p}<.05$ ) örgütsel desteğin aracı rolünün anlamlı olduğunu göstermektedir. Bu sonuçlara göre yöneticinin bilgi paylaşım davranışı ile bilgi paylaşımı sonucu değersiz olma kaygısı ilişkisinde örgütsel destek aracı etkiye sahiptir.

\section{Sonuç ve Tartışma}

$\mathrm{Bu}$ araştırmada yöneticinin bilgi paylaşımı davranışının çalışanın bilgi paylaşımı sonucu değersiz olma kaygısı üzerindeki etkisi ve algılanan örgütsel desteğin aracı rolü incelenmiştir. Yöneticinin bilgi paylaşımı davranışının, algılanan örgütsel destek aracılığıyla, çalışanın bilgi paylaşımı sonucu değersiz olma kaygısı üzerindeki katkısını görmek amacıyla yapılan analizlerin sonucunda yöneticinin bilgi paylaşımı davranışının, çalışanın bilgi paylaşımı sonucu değersiz olma kaygısı üzerinde anlamlı ve düşük düzeyde negatif katkı yaptığı görülmüştür. Bu sonuç, Doğan ve Kılıç'ın (2009) vurguladığı yöneticinin örgüt içerisinde bilgi paylaşımını teşvik etmedeki rolünü, bilgi paylaşımı konusunda rol model oluşturarak çalışanın bilgi paylaşımı sonucu değersiz olma kaygısının azaltması ile açıklar niteliktedir. Ancak analiz sonuçlarına göre yöneticinin bilgi paylaşım davranışı, çalışanın bilgi paylaşımı sonucu değersiz olma kaygısını üzerinde düşük düzeyde bir açıklayıcılığa sahiptir. Bu bulgu, çalışanın bilgi paylaşımı sonucu değersiz olma kaygısını üzerinde etkili olan başka unsurlar olduğunu düşündürmektedir. Bununla birlikte analiz sonuçlarına göre yöneticinin bilgi paylaşımı davranışının, algılanan örgütsel destek üzerinde yüksek düzeyde bir açıklayıcılığa sahiptir. Bu bulgu ise Rhoades ve Eisenberger (2002), Sluss (2008) ve Baranik (2009)'in, çalışanların yöneticilerinin kendilerine yönelik davranışlarından, örgütün kendisine verdiği değer yönünde bir algı geliştirdiğine dair araştırma sonuçları ile örtüşmektedir. 
Ayrıca, yöneticinin bilgi paylaşımı davranışı ve algılanan örgütsel destek birlikte ele alınarak çalışanın bilgi paylaşımı sonucu değersiz olma kaygısı üzerindeki açıklayıcılığına bakıldığında, yöneticinin bilgi paylaşımı davranışının açıklayıcılığının ortadan kalktığ1 görülmüştür. Yöneticinin bilgi paylaşımı davranışının başlangıçta olan katkısının ortadan kalkması, örgütsel desteğin ara değişken görevi gördüğünü ortaya koymaktadır. Bu bulgu, Sosyal Değişim teorisini ve Cabrera ve Cabrera (2005) ve Watson ve Hewet'i (2006) destekler şekildedir. Son olarak algılanan örgütsel desteğin çalışanın bilgi paylaşımı sonucu değersiz olma kaygısı üzerinde negatif ve orta düzeyde bir katkıya sahip olduğu görülmüştür. Bu bulgu ise, Janz and Prasarnphanich (2003)'in de belirttiği gibi, örgütün desteğini hisseden çalışanın kendisinde bulunan bilgiyi örgüt bilgisi haline getirmek konusunda daha istekli olabileceğine işaret etmektedir.

Yazında bir çok araştırma örgütsel desteğin aracı değişken rolüne sahip olduğunu göstermektedir. Örneğin Wayne vd. (1997) insan kaynakları faaliyetlerinin duygusal bağlılık, örgütsel vatandaşlık davranışı ve işten ayrılma eğilimi ile ilişkisinde, Allen vd. (1998) bağlılık ve karar verme süreçleri, iş güvenliği ve ödüllerin adil dağıtımı gibi değişkenler arasındaki ilişkide, Rhoades vd. (2001) ise bağlılık, örgütsel ödüller, prosedürel adalet ve yönetici desteği ile ilişkisinde, Eisenberger vd. (2002) yönetici desteği ve gönüllü işten ayrılma arasındaki ilişkide, Masterson vd. (2000) prosedürel adalet algısının bağlılık, iş tatmini ve işten ayrılma eğilimi üzerindeki ilişkide örgütsel desteğin aracı rolünü doğrulamışlardır (Çakar ve Yıldız, 2009). Bu bulgular çalışanlar tarafından algılanan örgütsel desteğin artmasıyla, işten ayrılma niyet gibi işletmeler açısından önemli bir çok unsur üzerinde olumlu yönde bir etkiye sahip olduğunu ortaya koymakta ve mevcut araştırma bulgularımızla örtüşmektedir. Araştırmamızın bulguları yöneticinin bilgi paylaşım davranışının, çalışanların algıladıkları örgütsel desteği arttırabileceğini ve bunun sonucunda bilgi paylaşımı sonucu değersiz olma kaygılarının azaltabileceğini göstermekte yani algılanan örgütsel desteğin arac1 rolünü doğrulamaktadır. Bu sonuç yöneticilerin çalışanlara rol model olmak bakımından ne derece önemli olduklarını ortaya koymaktadır. Çalışanın yöneticisini örnek alarak onun davranışlarını gösterme eğiliminde olmakta ve de yöneticisinden gördüğü olumlu muamele kendisinin de örgüt açısından olumlu ve pozitif davranışlara yönelmesini sağlamaktadır. Ayrıca çalışanın kurumun kodları hakkındaki bilgileri de yöneticisi aracılığıyla edindiği ve yöneticinin kurumun çok önemli bir yansıması olduğu sonucuna ulaşmak da mümkündür.

Demirel ve Seçkin (2011) örgütsel adaletin bilgi paylaşımı üzerindeki etkisini inceledikleri araştırmalarında, çalışanların özellikle terfi ve ödül sistemleri konusunda yöneticilerinin adil bir sistem kullanmalarının önemine değinmekte, bu beklentinin yöneticilere bilgi paylaşımını destekleyen ve ödüllendiren bir ortam yaratma rolü yüklediğini ifade etmektedirler. Bu bağlamda çalışanları en çok ilgilendiren konulardan biri olan terfi, ödül gibi unsurların hangi kural ve düzenlemelere tabi olduğunu iletmek ancak yöneticinin açık bir şekilde bilgi paylaşımını benimsemesi ile mümkün olabilecektir. Yöneticinin benimsediği bu tutum ise zamanla örgüt kültürüne yansıyacak ve bilgi paylaşımı doğal ve kabul gören bir davranış biçimi haline gelebilecektir. Demirel ve Seçkin (2011) bilgi paylaşımının algılanan örgütsel adaleti arttırmasının yanı sıra; dedikoduyu azaltarak önyargıların üstesinden gelinmesi, güven ve örgüte bağlılık sağlama, rekabet avantajı sağlayacak bilginin üretimi ve örtük bilginin ortaya çıkarılması gibi yararlar da sağlayacağını ifade etmektedir. Tüm bu süreçlerde kilit rolün yine yöneticiye ait olduğu da vurgulanmaktadır. 
Bu çalışma ile algılanan örgütsel desteğin öncellerine bir yenisi olan "yöneticinin bilgi paylaşım davranışı eklenmiş olup", algılanan örgütsel desteğin daha önce ele alınmamış olan bir bağımlı değişken olan "bilgi paylaşımı sonucu değersiz olma kaygısı" üzerinde azaltıcı etki yaptığı ortaya koyulmuştur. Böylelikle hem örgütsel destek hem de bilgi paylaşım alanının dinamiklerinin daha iyi anlaşılması yönünde yazına değerli bir bilgi sağlanmıştır.Bununla birlikte mevcut araştırmada açık bilginin inceleme konusu yapılmıştır. Köseoğlu vd. (2011), formal dille iletilemeyen örtük bilginin rekabet avantajı sağlamak konusunda önemli bir belirleyici olduğunu ifade etmektedirler. Örtük bilginin açığa çıkartılması ve paylaşımı ise açık bilgiye göre daha karmaşık bir süreç gerektirebilir. Açık bilginin güven, bağlılık, adalet gibi kavramlarla ilişkisi incelenmiş olsa da örtük bilginin ve yöneticinin bu süreçte nasıl bir rol oynayabileceği daha fazla araştırılmaya ihtiyaç duyan konulardan birisidir.

Bilginin türü kadar işletmenin faaliyet alanı da bilgi paylaşımının önemini etkilemektedir. Örneğin sağlık sektöründe tüm çalışanların; hekimler, hemşireler, sağlık yöneticileri ve diğer görevli personelin tıbbi hataları azaltmak, aynı hatanın tekrarını önlemek, sağlık bakım kalitesini geliştirmek gibi nedenlerle sıklıkla bilgi paylaşımına başvurdukları görülmektedir (Köseoğlu vd. 2011). Bu durum sektörden kaynaklanan farklılıkların yanı sıra mesleki özelliklerin de araştırılmasının önemini ortaya koymaktadır. Örneğin Köseoğlu vd. (2011) hekimler üzerinde gerçekleştirdiği araştırmasında bilgi paylaşım davranışının cinsiyet, yaş, pozisyon, unvan ve kurumdaki tecrübeye bağlı olarak farklılık göstermediğini ortaya koymuştur. Bu sonuç bazı mesleklerde meslek ahlakı gereği doğru olanı yapmak adına, söz konusu örnekte hastaların çıkarlarını korumak adına bilgi paylaşımını zorunlu kılmaktadır. Bilgi paylaşımının hangi meslek ya da faaliyet alanına göre farklılık gösterdiği araştırılmaya değer önemli bir araştırma sorusu olarak ortaya çıkmaktadır. Bilgi paylaşımını kaçınılmaz kılan meslek ya da işletmelerde yöneticinin ya da kurum uygulamalarının daha az önem kazanarak bireysel ahlaki yapının ön plana çıkması muhtemeldir. Rekabetin yoğun olduğu ya da iş gücü devir hızının yüksek olduğu bir işletmede ise kurumun bilgi paylaşımını destekleyecek bir kültürü teşvik etmesi ve yöneticinin rolü önem kazanabilecektir.

Alana ilgi duyan araştırmacılar yöneticinin başka hangi davranışları ile çalışana örnek oluşturduğunu, bu davranışların çalışan tarafindan ne şekilde yorumlandığı ve ne tür tutum ve davranışları etkilediği bakış açısıyla yeni araştırma modelleri tasarlayarak yönetim alanına önemli katkılar sağlayabileceklerdir. Bu çalışma kapsamında bilgi paylaşımı üzerinde etkili olduğu bilinen bilgi paylaşımına ilişkin örgüt kültürü araştırmaya dahil edilmemiştir. Yine yöneticiye, kuruma ve çalışma arkadaşlarına duyulan güvenin de bilgi paylaşım davranışı üzerinde etkili olabileceği akla gelmektedir. Gelecekte yapılacak çalışmalar bu değişkeni de dikkate alarak farklı yapılarda ve farklı alanlarda faaliyet gösteren firmalar açsısından sonuçları destekleyerek alana katkı sağlayabileceklerdir. 


\section{Kaynakça}

Baranik, L.E., Roling, E.A. and Eby L.T. (2010). "Why Does Mentoring Work? The Role of Perceived Organizational Support", Journal of Vocational Behavior, Volume: 76, Issue 3. p.366-373.

Baskerville, R.and Dulipovici, A. (2006). "The theoretical foundations of knowledge management". Knowledge Management Research \& Practice, Volume: 4, Issue: 2, p.83-105.

Baron, R.M. and D.A. Kenny. (1986). "The Moderator-Mediator Variable Distinction in Social Psychological Research: Conceptual, Strategic and Statistical Considerations". Journal of Personality and Social Psychology. Volume: 51, Issue: 6. p.1173-1182.

Cabrera, E. F. and Cabrera, A. (2005). "Fostering Knowledge Sharing Through People Management Practices". The International Journal of Human Resource Management, Volume: 16, Issue :5, p.720-735.

Caesens,G., Marique,G. Hanin,D. and F. Stinglhamber. (2016). "The Relationship between Perceived Organizational Support and Proactive Behaviour Directed Towards the Organization". European Journal of Work and Organizational Psychology. Volume: 25, Issue: 3. p.398-411.

Connelly, C.E and Kelloway E.K. (2003). "Predictors of Employees' Perceptions of Knowledge Sharing Cultures". Leadership \& Organizational Development Journal, Volume:24, Issue: 5. p.294-301.

Constant, D., Kiesler, S. and Sproull, L. (1994). "What's Mine is Ours, or is it? A Study of Sttitudes about Information Sharing". Information systems research, Volume:5, Issue: 4. p.400-421.

Çakar,N.D. ve S.Yıldız. (2009). “Örgütsel Adaletin İş Tatmini Üzerindeki Etkisi: Algılanan Örgütsel Destek Bir Ara Değişken Mi?” Elektronik Sosyal Bilimler Dergisi. 8,28. 58-90.

Davenport, T.H. ve Prusak L. (1998). Working Knowledge: How Organizations Manage What They Know. Harvard Business School Press, Boston.

Demirel Y., Seçkin Z. (2011). Örgütsel Adaletin Bilgi Paylaşımı Üzerine Etkisi: İlaç Sektörü Çalışanlarına Yönelik Bir Araştırma. Bilig. 56. 99-119.

Dfouni, M. and Croteau, A-M. (2003). Knowledge Management Technological Issues, Roles and Obstacles: An International Web-Based Delphi Study. The Concordia University Department of Decision Sciences and MIS, John Molson School of Business, Quebec, Canada.

Doğan,S ve Kılıç S. (2009). "Bilgi Yönetiminde Yöneticinin Rolü üzerine Kavramsal bir İnceleme". Süleyman Demirel Üniversitesi İktisadi İdari Bilimler Dergisi, Volume: 14,Issue: 2. s. 87-111.

Durmuş,V. Ve B. Şahin. (2015). "Hastanelerde Algılanan Örgütsel Destek ile Örgütsel Öğrenme Arasındaki İlişkinin Belirlenmesine Yönelik bir Araştırma”. TAF Preventive Medicine Bulletin.Volume: 14, Issue: 6. s.438-447. 
Dursun,E. (2016). “The Relation between Organizational Trust, Organizational Support and Organizational Commitment". African Journal of Business Management. Volume: 9,Issue: 4. p.134-156.

Eisenberger, R., Huntington, R., Hutchison, S., and D. Sowa. (1986). "Perceived Organizational Support". Journal of Applied Psychology, Volume:71, Issue: 3. p. 500-507.

Eisenberger, R., Armeli, S., Rexwinkel B.,Lynch, P.D. and L.Rhoades (2001). "Reciproration of Perceived Organizational Support". Journal of Applied Psychology, Volume: 86,Issue: 1. p.42-51.

Gee-Woo B., Zmud, R. W., Young-Gul K. and Jae-Nam Lee. (2005). "Behavioral Intention Formation in Knowledge Sharing: Examining the Roles of Extrinsic Motivators, Social-psychological Forces, and Organizational Climate". MIS Quarterly, Volume: 29, Issue: 1. p.87-111.

Hislop, D. (2003). "Linking Human Resource Management and Knowledge Management via Commitment: A Review and Research Agenda". Employee relations, Volume: 25, Issue: 2, p.182-202.

Howes, J.C., Cropanzano R., Grandey A.A. and C.J. Mohler. (2000). "Who is Supporting Whom? Quality Team Effectiveness and Percieved Organizational Support”. Journal of Quality Management, Volume:5, Issue: 2. p.207-223.

Holthouse, D. (1998). "Knowledge Research Issues". California Management Review, Volume: 40, Issue:3. p. 277-280.

Holste, J. S. and Fields, D. (2010). "Trust and Tacit Knowledge Sharing and Use". Journal of knowledge management. Volume: 14, Issue:1. p. 128-140.

Janz, B. D. and Prasarnphanich, P. (2003). "Understanding the Antecedents of Effective Knowledge Management: the Importance of a Knowledge-Centered Culture". Decision Sciences, Volume:34, Issue: 2, p.351-384.

Kalidass, A. And A. Bahron. (2015). “The Relationship between Perceived Supervisor Support, Perceived Organizational Support, Organizational Commitment and Employee Turnover Intention". International Journal of Business Administration. Volume: 6, Issue: 5. p.82-89.

Khurram, S. (2009). "Perceived Organizational Support, Antecedents and Consequences Proposing and Testing a Model in a Public Sector University of Pakistan”. South Asian Journal of Management, Volume:16, Issue: 1. p. 7-26.

Kirckpatrick, D. (1998). “The Second coming of Apple”, Fortune, 138, p.90.

Köseoğlu,M.A., Gider, Ö., ve S. Ocak. (2011). "Bilgi Paylaşımı Tutumunu Etkileyen Faktörler Nelerdir? Bir Kamu Hastanesi Örneği”. Eskişehir Osmangazi Üniversitesi İIBF Dergisi. 6,1. 215-243.

Leonard, D and Sensiper,S (1998). "The Role of Tacit Knowledge in Group Innovation”. California Management Review, Volume: 40. Issue: 3, p.112-132.

Lumbantobing P., Sule, E.T., Tjakraatmadja, J.H., Yunizar and J. Purwanti. (2015). "Leadership Behavior, Perceived Organizational Support, Knowledge Sharing Intensity, and Knowledge Satisfaction: Study on the Headquarters of 3 State- 
Owned Enterprises That Implement Knowledge Management”. European Conference on Knowledge Management: p.484-495. Kidmore End: Academic Conferences International Limited.

Mabasa,F.D. and H. Ngirande (2015). "Perceived Organisational Support Influences on Job Satisfaction and Organisational Commitment Among Junior Academic Saff Members". Journal of Psychology in Africa. Volume:25, Issue:4. p.364-366.

Nahapiet, J., and Ghoshal, S. (1998). "Social Capital, Intellectual Capital, and the Organizational Advantage". Academy of management review, Volume: 23, Issue: 2, p.242-266.

Nonaka, I. (1991). “The Knowledge-Creating Company". Harvard Business Review, Volume: 69, Issue: 6. p. 96-104.

Nonaka, I. (1994). “A Dynamic Theory of Organization Knowledge Creation”. Organization Science, Volume:5, Issue: 1. p. 14-37.

Nigel O.; Abell A and Ward S. (1999). "KM in Practice 50 Years of Experience". The Second International CKO Summit Executive Report, March, Luttrellstown, Castle Dublin, Ireland.5.

O’dell C., Grayson C.J. ve Essaides N. (2003). "Ne Bildiğimizi Bir Bilseydik”. Dışbank Kitaplar1-3. 1. Basım.

Oldham, G. R. (2003). "Stimulating and Supporting Creativity in Organizations". Managing knowledge for sustained competitive advantage, p.243-273.

Renzl,B. (2008). "Trust in Management and Knowledge Sharing: The Mediating Effects of Fear and Knowledge Documentation", Omega The International Journal of Management Science, Volume:36, Issue: 2. p. 206-220.

Sluss D.M., Klimchak M. and J. J. Holmes. (2008). "Perceived Organizational Support as a Mediator between Relational Exchange and Organizational Identification". Journal of Vocational Behavior, Volume.73, Issue: 3. p.457-464.

Szulanski, G. (1996), "Exploring Internal Stickiness: Impediments to the Transfer of Best Practice Within the Firm", Strategic Management Journal, Volume: 17. Winter special issue, p.24-43.

Swap, W., Leonard, D., and Mimi Shields, L. A. (2001). "Using Mentoring and Storytelling to Transfer Knowledge in the Workplace". Journal of management information systems, Volume: 18, Issue:1, p.95-114.

Stenmark, D. (2000). "Leveraging Tacit Organizational Knowledge". Journal of management information systems, Volume: 17, Issue: 3, p.9-24.

Trauth, E. M. (1999). "Who Owns My Soul? The Paradox of Pursing Organizational Knowledge in a Work Culture of Individualism". In Proceedings of the 1999 ACM SIGCPR conference on Computer personnel research,159-163.

Watson, S., and Hewett, K. (2006). "A Multi-Theoretical Model of Knowledge Transfer in Organizations: Determinants of Knowledge Contribution and Knowledge Reuse". Journal of management studies, Volume: 43, Issue:2, p.141-173. 


\section{The Effect of Knowledge Sharing Behavior of Supervisor on Employees' Fear of Losing Value Regarding Knowledge Sharing: The Mediating Role of Organizational Support}

\author{
Gül Eser \\ Marmara University, \\ Department of Business Management \\ Ressam Namık İsmail Sok. No.1 \\ Bahçelievler/ İstanbul, Turkey \\ guleser@marmara.edu.tr
}

\author{
M. Şebnem Ensari \\ Nişantaşı University, Faculty of \\ Economics and Administrative Sciences, \\ Nişantaşı Kampüsü, Ergenekon Cad. No: \\ 45, Şişli / İstanbul, Turkey \\ sebnemensari@gmail.com
}

\section{Extensive Summary}

\section{Introduction}

Knowledge sharing is an important issue in organizations because the knowledge of employee is expected to become the knowledge of organization. Employee may leave the organization but the knowledge is to be embedded in organizational structure. Supervisors are seen as key actors in this process. It is suggested that supervisor represents the whole organization and therefore her/his role is being examined (Nonaka, 1994; Nigel et.al. 1999; Dfouni and Croteau, 2003; Connelly and Kelloway 2003). We base our study on this notion and social exchange theory and we suggest that knowledge sharing behavior of supervisor will make employees feel higher levels of organizational support and this in return will enhance the knowledge sharing behavior of the employee.

Eisenberger et.al. (2001) describe perceived organizational support as “...general beliefs of employees concerning how much the organization values their contribution and cares about their well-being." According to Nonoka (1991, 1994) knowledge sharing is the process of revealing tacit information. Holtshouse (1998) states that turning individual's knowledge into group knowledge can also be defined as knowledge sharing. Renzl (2008) states that an employee's fear of becoming worthless can effect the knowledge sharing behavior and revealing tacit information which can be useful for organization. Research results reveal that knowledge sharing can enhance firm's performance (Dfouni and Croteau 2003). Here Connelly and Kelloway (2003) in their paper entitled "Predictors of Employees' Perceptions of Knowledge Sharing Cultures" show that support of supervisor regarding knowledge sharing effects the knowledge sharing behavior in whole organization.

Several studies aim to reveal the principals of knowledge sharing and revealing the tacit knowledge. Here we suggest that supervisor will act as a role model and encourage employees to share their knowledge with others. It is very common that knowledge is considered as power. Therefore it is likely that people will not share information with the fear of losing value. When a supervisor is eager to share information this will give some clue to employee about organization's culture and it is likely that this employee will infer this behavior as a safe and supportive manner of organization toward employees. 


\section{Method}

In order to test the effect of "knowledge sharing behavior of supervisor" on "fear of losing value regarding knowledge sharing" and the mediating role of organizational support we conducted a survey on 200 participants. Our survey tool was consist of four main parts that measured demographic characteristics and our three variables. Organizational support was measured through Eisenberger et.al.'s (1986) scale (8 items). Knowledge sharing of supervisor was measured with Gee-Woo et.al.'s (2005) scale ( 7 items) and finally fear of losing value regarding knowledge sharing is measured with Renzl's (2008) scale (4 items).

\section{Findings}

$\% 41,9$ of participants are female and $\% 58,1$ are male. $\% 44,7$ is married and $\% 55,3$ is single. $\% 3,2$ graduated from elementary school, \%11,1 from high school, $\% 60,4$ have collage degree, \%20,3 have master degree and \%5,1 Ph.D. Their positions in the firms is as follows; \%25,8 low level, \%55,3 middle level and \%18,9 are from high levels of firm. \%10,6 are from public and \% 89,4 from private sector. Their work experience is found to be between 1 and 41 years. Their tenure is between 1-28 years.

To be able to see the relationships between variables we conducted correlation analysis. Results show that there is a positive correlation between supervisor's knowledge sharing and organizational support. Negative correlations was found between supervisor's knowledge sharing and fear of losing value. Also organizational support and fear of losing value revealed a negative correlation. These results can be interpreted such as when information sharing behavior of supervisor rises so does the perceived organizational support and conversely decreases the fear of losing value. Besides when perceived organizational support rises, fear of losing value decreases.

We tested our model and the mediating role of variable according to Baron and Kenny (1986) with SPSS program and also ran a Sobel test. We ran four regression analysis in order to test the mediating role of organizational support. First we conducted regression analysis for knowledge sharing of supervisor and fear of losing value (p: 0.02; Adj.R squ.: ,018, $\beta:-, 150$ ). Than we ran regression analysis for knowledge sharing of supervisor and perceived organizational support (p: .000; Adj.R squ.: ,404; $\beta:, 638$ ). Third regression analysis was to see the effect of both knowledge sharing of supervisor and organizational support on fear of losing value. Results revealed that when both variables were included the effect of knowledge sharing of supervisor's effect disappeared ( $p$ : .390) meaning organizational support is a mediating variable between two. Our results of analysis revealed that organizational support perfectly mediates the relationship between knowledge sharing of supervisor and fear of losing value regarding information sharing.

Our results support our model and the key role of supervisor and organizational support is once again revealed. Our findings reveal that employees tend to generalize their relationship and experiences with supervisor to whole organization and they mirror this to others. This result is in line with findings of Rhoades and Eisenberger (2002), Sluss (2008) and Baranik (2009) and Doğan and Kılıç (2009) who conclude supervisor is a reflection of the whole organization for employee. Also the importance of organizational support is once again revealed in terms of social exchange theory. Once person receives a favor that person is prone to pay back. This result is also in 
accordance with Cabrera and Cabrera (2005) and Watson and Hewet (2006) research findings.

We tested our model and the mediating role of variable according to Baron and Kenny (1986) with SPSS program and also ran Sobel test. Results of analysis revealed that organizational support perfectly mediates the relationship between knowledge sharing of supervisor and fear of losing value regarding information sharing.

\section{Conclusion and Discussion}

Our study adds to literature that for employees to share information first a role model is needed. It is very likely that this role model can be the immediate manager of employee. Once this role model exhibits a behavior it is very likely that employees will also be keen on doing the same thing. Speed of doing favor is too high and it is contagious. Lately positive organizational behavior is becoming so popular and the effects of variables such as positive leadership is being examined. This study also finds support for social exchange theory that when our firm is kind to us we would like to pay this back. Our study supports the idea that if a firm wants to keep its employees and also wants their knowledge to become organization's knowledge, it has to maintain proper conditions first, namely making employees feel they are supported and their contributions are important. Once an employee feels this support the hostile emotions are gone away, he or she is ready to pay back to organization. This way supervisor and organization's manner toward employees may predict and guide employees to desired outcomes such as sharing information.

One thing that prevents employees from sharing information is fear of losing value. It is a common feeling that when we think something can only be done by us, we are indispensable. This assumption is the main barrier to knowledge sharing and the only solution is to make employees feel comfortable that even their knowledge becomes organization's knowledge, they are still valuable and their efforts still matters. It won't be easy to convince employees especially in the economic conditions where there are many candidates and rivals wishing to be at their positions. However a role model can act as an evidence of firm's goodwill and employees will start to mirror their supervisor's behavior. In this study we did not consider the culture regarding knowledge sharing. Culture, norms and policies are also mentioned to be important predictors of knowledge sharing behavior. Future studies may consider culture and climate in order to test their effect and results on knowledge sharing behavior of employees. 